\title{
ADDITION OF HYDROFOIL TO SHIP RESISTANCE ANALYSIS ON HALASAN CLASS BASED ON VALIDATION TEST RESULT
}

\author{
Sutrisno, Wawan Kusdiana, Ayip Rivai, Muhammad Askhuri \\ Indonesian Naval Technology College, \\ Bumimoro-Morokrembangan, Surabaya 60187, Indonesia
}

\begin{abstract}
KRI Halasan - 630 is one of the Fast Missile warships with a length of 60 Meters which apart of fast patrol boat class which belongs to TNI-AL. Accordance with the main function not only as a fast missile boat but also as a patrol ship killer, this ship was made to have a high ability in "hit and run". Since the beginning of the manufacture and after being inaugurated as KRI in 2014 this ship is able to reach speed until 27 knot in full load. As time goes on the same conditions the speed that this ship can achieve is 25 knot at maximum speed. This can be caused by increase in value from the resistance of the ship. One way to reduce the value of the resistance of the ship is to minimize the Wet Surface Area(WSA) from the ship. By adding hydrofoil technology will produce lift force which could lift apart of the hull ship from the water so that Wet Surface Area from the ship will reduce. From the calculation, to lift on the hull of KRI Halasan Class $20 \mathrm{~cm}$ in full load condition at $25 \mathrm{knot}$ knows that dimension for fore foil with tapered straight type are wingspan 4,6 m, wingroot 1,33 m, wingtip 0,5 $\mathrm{m}$, and swept angle $11^{\circ}$. And dimension for aft foil with rectangular straight type are wingspan 5,3 $\mathrm{m}$, wingroot and wingtip $1,365 \mathrm{~m}$, and swept angle $0^{\circ}$. The ship resistance with hydrofoil is $265,5 \mathrm{KN}$, while in the same condition and speed from the ship without hydrofoil the value of ship resistance is $267 \mathrm{KN}$. By adding hydrofoil technology could reduce the ship resistance 1,5 KN. This values could make 19,29 KW or 25,86 Hp in power saving.
\end{abstract}

Keywords : Hydrofoil technology, Ship Resistance, Halasan Class

\section{INTRODUCTION.}

As a type of Fast Ship owned by TNI-AL is the KCR Halasan class, which has a length of $60 \mathrm{~m}$. Especially for KCR Halasan Class is done of the nation's children, where shipbuilding is carried out by their own domestic shipyards. The slogan "Hit and Run" is the slogan that is owned by this Fast Ship Unit. Now a day a decrease in speed from the Halasan Class KCR is happen. One way that can be done in increasing the speed of the KCR Halasan Class is to minimize the resistance on the ship's body. Some things that can be done to minimize the resistance of the ship are with:

a. Make small dimensions on the body of the ship that is exposed to or in contact with seawater such as the Catamaran and Trimaran ship.

b. Make an air cushion on the body of the ship like a hovercraft.

c. Using hydrofoil wings on the hull of the ship which will later be able to make the ship's body above the water, so the value of the resistance will also decrease.

d. Using SWATH (Small Waterplane Twin Hull Area) technology.

In this study the research used the hydrofoil method to reduce the resistance between the water and the ship's body. With the presence of these wings will lift part or all of the ship's body (Foil Borne) which will directly reduce water friction with the ship's body. The addition of hydrofoil is made so that the ship's body can be partially lifted. With this lift, it is expected that the resistance value will decrease and the Halasan class KCR can fulfill its function as a fast ship that has the slogan "Hit and Run". The problems that arise from the addition of hydrofoil are:

a. What is the dimensions of the hydrofoil wing used to lift the ship's body by $20 \mathrm{~cm}$ in full load at 25 knots?

b. How is the value of ship resistance on KRI Halasan class after addition of hydrofoil?

The addition of wings on the KCR 60 will not only make the total resistance value (RT) also result in an increase in the total resistance value (RT) on the ship because in addition to the lift force produced from the wing will also produce a drag force, where the drag force is also known as force swipe between fluids with the ship's body. Before adding the hydrofoil wing, of course what must be done is to design the wings that will be added later, and when designing a wing it must be understood the basic science principles of aerodynamics.

a. The principle of the lift force caused by the hydrofoil wing actually occurs due to the pressure difference between the upper surface and the lower surface of a wing. This is known from an experiment conducted by Bernouli on a venturi tube. 


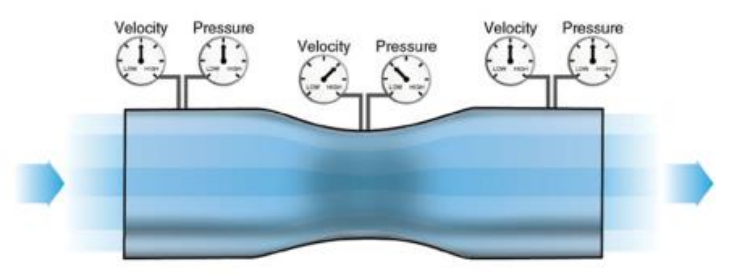

Fig 1. Venturi tube experiment (Source: Nugroho, 2008).

From the description of the Bernouli principle it is clear that if a fluid flows from a large surface area to a small surface area the flow velocity value will increase but the flow pressure value will decrease. Bernouli equation is also an integration of Euler's equation

$$
-\frac{1}{\rho} \frac{\partial P}{\partial S}-g \frac{\partial Z}{\partial S}=\frac{\partial V}{\partial t}+V \frac{d V}{d S}
$$

If fluid particles move as far as dS along the stream line and flow is considered steady, then :

$$
-\frac{1}{\rho} d P-g d Z=V d V
$$

or

$$
\frac{d P}{\rho}+g d Z+V d V=0
$$

While for incompresible flow, where $\rho$ is considered constant, then:

$$
\frac{P}{\rho}+g Z+\frac{V^{2}}{2}=0
$$

Where for the flow form is steady, flow without friction, incompresible flow, and flow along the stream line.

b. Foil is a basic constituent component of a wing, and from this foil the force of lift is generated. Parts of a foil.

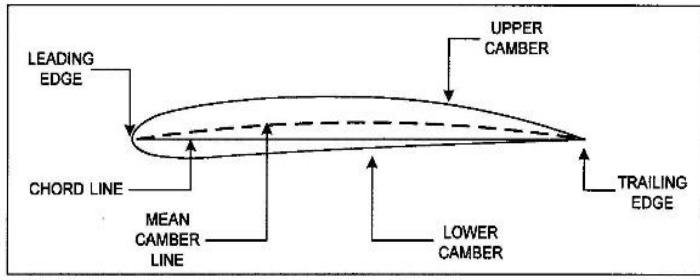

Fig 2 Parts on foil

(Source: Denns, 2015).

The use of Angle of Attack on the application of a wing also affects the magnitude of the lift force caused, the greater the AOA used the greater the force of lift produced, but still within the AOA maximum limit used.

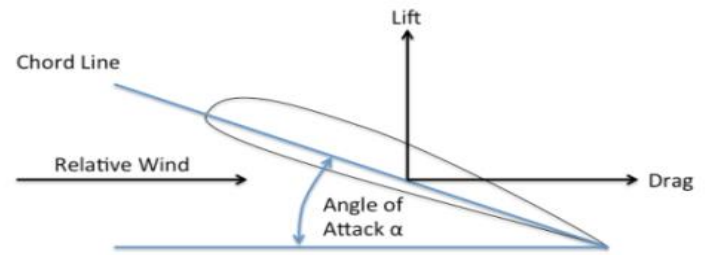

Figure 3 Illustration of Angle of Attack (Source: Aviation Chief, 2017).
The effect with the formation of angle of attack or Angle of attack will make the flow velocity above the surface of the foil will be higher than below the surface of the foil, while for the pressure under the foil will be greater than the pressure above the foil surface. This large pressure from below is the lift or lift. So that it can be concluded the lift force :

$$
F L=1 / 2 \rho \times V^{2} \times S \times C_{L}
$$

The use of AOA that exceeds the standard will actually eliminate the lift force or what is known as stall. The maximum AOA limit used depends on the type of foil used.

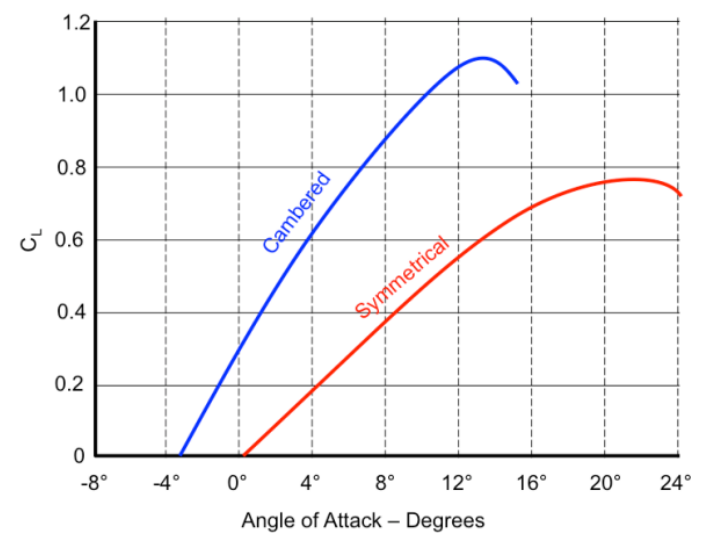

Fig 4. $\mathrm{AOA}$ comparison chart with $\mathrm{CL}$ (Source: Aviation Chief, 2017).

The choice of foil, either cambered foil or symmetrical foil depends on the choice of each designer, while still taking into account the characteristics of each foil used. In contrast to lift, this drag force vector direction is parallel to fluid flow and the direction of this force is always in line with the fluid flow.

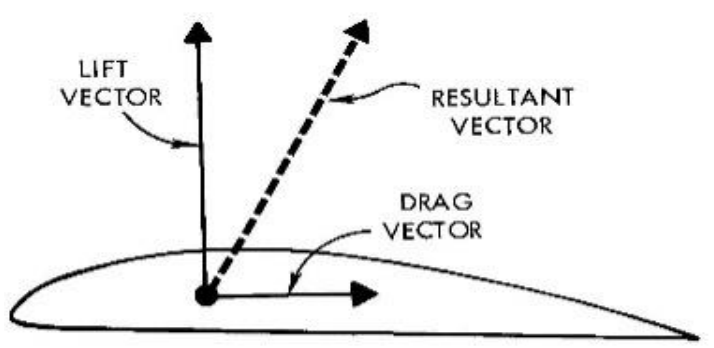

Fig 5. Illustration of drag force (Source: Suseno, 2013)

From this definition it can be said that this drag force is a resistance contained in a foil. The force on this foil is due to the friction between the fluid and the foil surface it passes through. The amount of drag can be defined:

$$
F D=1 / 2 \rho \times V^{2} \times S \times C_{d}
$$

The various forms of hydrofoil wings are designed so that they not only get the desired lift force but also can be met in terms of aesthetics. 
Here are some examples of the shape of wings on hydrofoil.

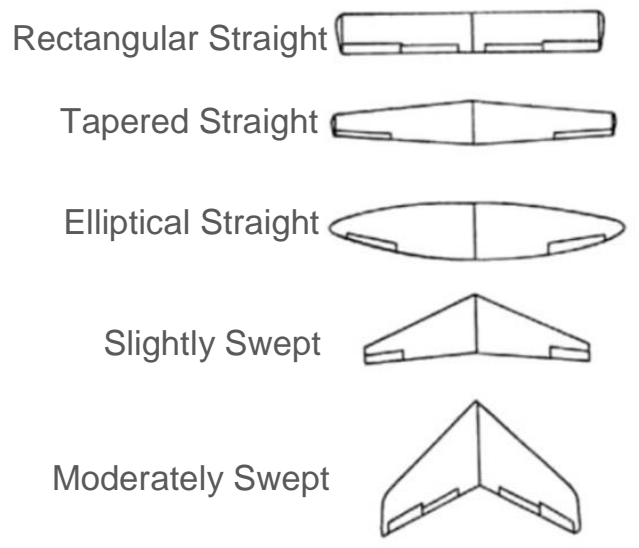

Fig 6. Wing shapes

(Source: Designing-smooth-symmetricalairfoil-wings-flite-test)

After knowing the shapes of the wings, parts of a wing must also be understood. Next is part of a wing.

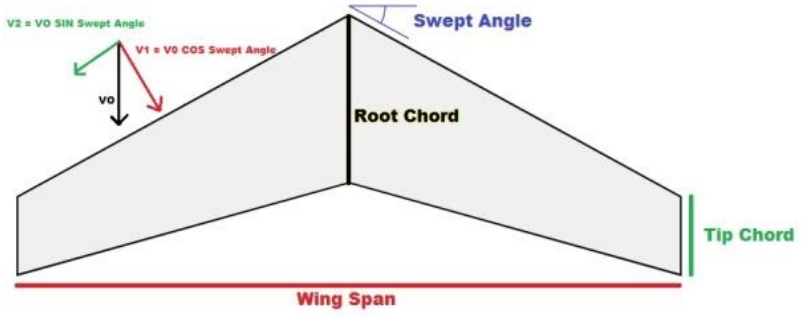

Figure 7. Geometry of a wing.

As for the placement or location of hydrofoil feet which are generally used are as follows.
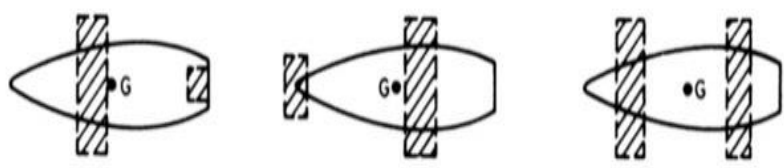

Fig 8. Placement of Hydrofoil legs (Source: K.J Rawson, 2001).

In the left picture is the placement of conventional hydrofoil legs, where $65 \%$ or more weight of the ship is supported by the front foil. In the middle image canard placement of hydrofoil leg, where $65 \%$ or more weight of the vessel is supported by the rear foil. In the right picture is a tandem hydrofoil leg placement, where for the entire weight of the ship is divided evenly by the front and rear foils.

\section{MATERIALS AND METHODS}

Research literally means as a series of activities carried out to see, look for, or observe things to get the desired results. In this study the author wrote a quantitative study in which this study was conducted focusing on certain parts, existing phenomena and relationships - relationships. The part that becomes central in this study is the measurement process because of these measurements include the observation process and also mathematical calculations. So clearly in this study using numbers as the main data to find what you want to know.

\subsection{Data Collection Methods}

The data collection technique that the author carried out was:

a. Search for all technical data from the manual.

b. Determine the foil used for wings and strut (wing support poles) with NACA standards.

c. Look for the characteristics of each foil used in the specified AOA.

d. Collecting the KCR 60 hydrostatic data from $2.6 \mathrm{~m}$ and $2.4 \mathrm{~m}$.

e. Look for linesplane KCR 60 data.

f. Looking for KCR 60 CoG data.

g. Using a fully submerged hydrofoil type.

h. Use two wings and determine the distance of the front and rear wings of the CoG.

i. Looking for formulation in determining $\mathrm{CL}$ from a wing.

j. $\quad$ Using the formulation of the lift force.

k. Using the formulation of drag force.

I. Using the formulation of total resistance calculations.

\subsection{Data Analysis Methods}

a. Calculate the displacement difference in draught $2.6 \mathrm{~m}$ with $2.4 \mathrm{~m}$, then the results are converted into the form of force calculations.

b. Determine the distance between the fore and aft wings of the ship's CoG.

c. Determines the magnitude of the force supported by the fore and aft wings using the principle of technical mechanics. The value of the force obtained is the value of the lift force that must be produced on the fore and aft wings. The calculation results show that $65 \%$ or more of the force load is supported by the rear wing, and is included in the canard type hydrofoil leg.

d. Design the fore and aft hydrofoil.

e. Calculates $C L$ on the fore and aft hydrofoil.

f. Calculates the speed value on the fore and aft wings. What is meant here is that later the lift force that must be produced by the fore and aft hydrofoil must work at the same speed.

g. Calculates the drag force produced by the hydrofoil and front and rear struts.

h. Calculates the total resistance of the ship in the presence of a drag force due to the addition of hydrofoil.

\section{RESULTS AND DISCUSSION}

Step:

a. Calculate the lift force produced by the fore and aft hydrofoil.

From the hydrostatic data of the ship, the difference in displacement between $2.6 \mathrm{~m}$ and 2.4 draught is 
66.74 Tons, then this value is converted to 654.719 $\mathrm{KN}$.

b. Calculates the force supported by the fore and aft hydrofoil.

Calculations are carried out using the principle of engineering mechanics. Obtained for the force supported by the fore hydrofoil $249.56 \mathrm{KN}$, while for the aft hydrofoil $405.16 \mathrm{KN}$.

c. Determine the lift force.

The force supported both on the fore and aft hydrofoil is the value of the lift force that must be produced by the fore and aft hydrofoil later.

d. Determine the shape and dimensions of the fore hydrofoil.

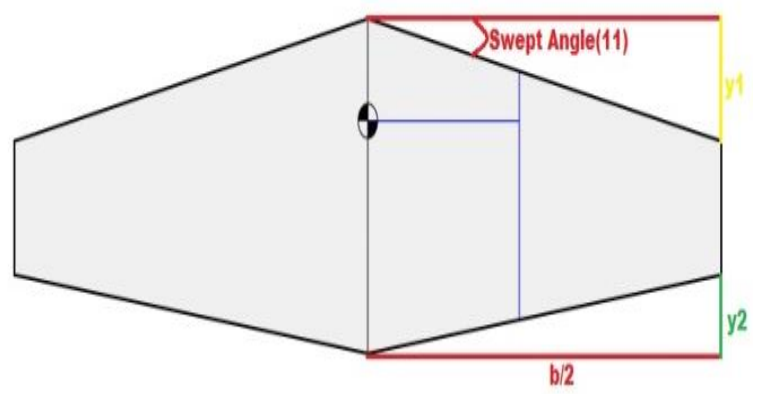

Tapered Straight Wing as a type fore hydrofoil. Data from the image when inserted into the table becomes:

Table 1. Dimension of fore hydrofoil.

DIMENSION OF FORE HYDROFOIL

\begin{tabular}{cc}
\hline $\begin{array}{c}\text { Wing Span } \\
(\mathrm{m})\end{array}$ & 4,6 \\
$\begin{array}{c}\text { Root Chord } \\
(\mathrm{m})\end{array}$ & 1,33 \\
$\begin{array}{c}\text { Tip Chord } \\
(\mathrm{m})\end{array}$ & 0,5 \\
$\begin{array}{c}\text { Swept Angle } \\
\left({ }^{\circ}\right)\end{array}$ & $11^{0}$ \\
\hline
\end{tabular}

e. Determine the shape and dimensions of the aft hydrofoil.

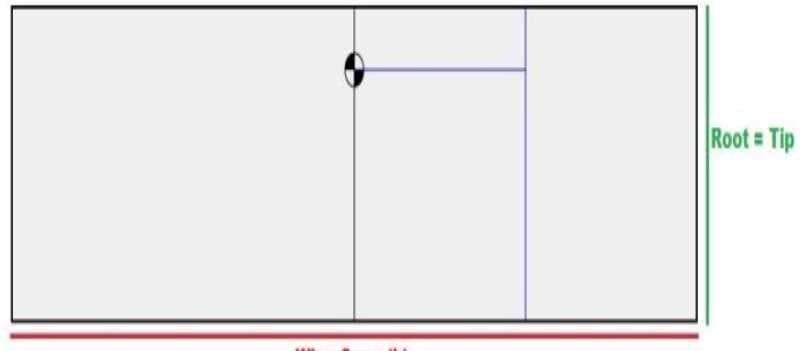

For the aft hydrofoil use a type Rectangular Straight Wing. The data is labeled as:
Tabel 2. Dimension of aft hydrofoil.

DIMENSION OF AFT HYDROFOIL

\begin{tabular}{cc}
\hline $\begin{array}{l}\text { Wing Span } \\
(\mathrm{m})\end{array}$ & 5,3 \\
$\begin{array}{c}\text { Root Chord } \\
(\mathrm{m})\end{array}$ & 1,365 \\
$\begin{array}{c}\text { Tip Chord } \\
(\mathrm{m})\end{array}$ & 1,365 \\
$\begin{array}{c}\text { Swept Angle } \\
\left({ }^{\circ}\right)\end{array}$ & $0^{0}$ \\
\hline
\end{tabular}

f. Calculates the lift coefficient $(\mathrm{CL})$ produced by the fore and aft hydrofoil. From the calculation process the value of $\mathrm{CL}$ is obtained:

Table 3. Value of $C_{L}$

\begin{tabular}{cc}
\hline & $\mathrm{C}_{\mathrm{L}}$ \\
\hline Fore Hydrofoil & 0,72 \\
\hline Aft Hydrofoil & 0,66 \\
Fore Strut & 0 \\
Aft Strut & \\
Aft Strut $_{2}$ & 0 \\
\hline
\end{tabular}

g. Calculates the speed that works on the fore and aft hydrofoil. This calculation is intended so that the resulting lift force works at the same speed. Lift calculation for fore hydrofoil :

$$
\begin{aligned}
F L & =1 / 2 \rho \times V^{2} \times S \times C_{L} \\
2 \times F_{L} & =\rho \times V^{2} \times S \times C_{L} \\
V^{2} & =\frac{2 \times F_{L}}{\rho \times S \times C_{L}} \\
V & =\sqrt{\frac{2 \times F_{L}}{\rho \times S \times C_{L}}} \\
& =\sqrt{\frac{2 \times 249.560}{1.025 \times 4,21 \times 0,72}} \\
& =\sqrt{\frac{499.120}{3.106,98}} \\
& =\sqrt{160,64} \\
& =12,64 \mathrm{~m} / \mathrm{s}
\end{aligned}
$$

For the fore hydrofoil because of the type of Tapered Straight, the speed which mean is the speed that is perpendicular to the plane, while the results above are not velocities perpendicular to the plane that the fluid passes through. So to find a speed that is perpendicular to the plane of the hydrofoil:

$$
V_{0}=V_{1} \cos \Lambda
$$




$$
\begin{aligned}
& V_{1}=\frac{V_{0}}{\cos \Lambda} \\
& V_{1}=\frac{12,64 \mathrm{~m} / \mathrm{s}}{\cos 11^{\circ}} \\
& \qquad V_{1}=\frac{12,64 \mathrm{~m} / \mathrm{s}}{0,98} \\
& V_{1}=12,89 \mathrm{~m} / \mathrm{s} \\
& 12,89 \mathrm{~m} / \mathrm{s}=25,06 \mathrm{Knot} .
\end{aligned}
$$

Lift calculation for aft hydrofoil.

$$
\begin{aligned}
F L=1 / 2 & \rho \times V^{2} \times S \times C_{L} \\
2 \times F_{L} & =\rho \times V^{2} \times S \times C_{L} \\
V^{2} & =\frac{2 \times F_{L}}{\rho \times S \times C_{L}} \\
V & =\sqrt{\frac{2 \times F_{L}}{\rho \times S \times C_{L}}} \\
& =\sqrt{\frac{2 \times 405.157,5}{1.025 \times 7,23 \times 0,66}} \\
& =\sqrt{\frac{810.315}{4.891,09}} \\
& =\sqrt{165,67} \\
& =12,871 \mathrm{~m} / \mathrm{s}
\end{aligned}
$$

$12,871 \mathrm{~m} / \mathrm{s}=25,02 \mathrm{Knot}$.

Unlike the for hydrofoil, because of the Rectangular Staright aft hydrofoil, the resulting velocity is a speed perpendicular to the plane.

h. Calculates the drag force produced by wings and strut. From the results of the calculation obtained the value:

Table 4. The total drag force produced by wings and strut.

\begin{tabular}{cc}
\hline & $\begin{array}{c}F_{D} \\
(\mathrm{KN})\end{array}$ \\
\hline Fore Hydrofoll & 15,9 \\
Aft Hydrofoil & 30,4 \\
Fore Strut & 0,064 \\
Aft Strut & 0,066 \\
Aft Strut & 0,066 \\
& $\sum F_{D}=46,5$ \\
\hline
\end{tabular}

i. Calculates the total resistance of the vessel with the addition of a hydrofoil wing.

$$
\begin{aligned}
R_{T \text { total }}= & R_{T \text { at } 25 \text { knot on draught } 2,4} \\
& \quad+\text { Drag } \text { Total }_{\text {wing and strut }} \\
= & 219 \mathrm{KN}+46,5 \mathrm{KN} \\
= & 265,5 \mathrm{KN} .
\end{aligned}
$$

After writing and numerical calculations about the hydrofoil addition analysis on the KRI Halasan Class, a number of things can be concluded:

a. The wing dimensions that can lift the KRI Halasan class for $20 \mathrm{~cm}$ in full load conditions at 25 knots are:

\begin{tabular}{ccccc}
\hline & $\begin{array}{c}\text { Wing } \\
\text { Span } \\
(\mathrm{m})\end{array}$ & $\begin{array}{c}\text { Wing } \\
\text { Root } \\
(\mathrm{m})\end{array}$ & $\begin{array}{c}\text { Wing } \\
\text { Tip } \\
(\mathrm{m})\end{array}$ & $\begin{array}{c}\text { Swept } \\
\text { Angle } \\
\left({ }^{\circ}\right)\end{array}$ \\
\hline $\begin{array}{c}\text { Fore } \\
\text { Hydrofoil }\end{array}$ & 4,6 & 1,33 & 0,5 & 11 \\
$\begin{array}{c}\text { Aft } \\
\text { Hydrofoil }\end{array}$ & 5,3 & 1,365 & 1,365 & 0 \\
\hline
\end{tabular}

b. The total resistance value (RT) produced by the $\mathrm{KRI}$ Halasan Class at full load conditions at the speed of 25 knots is $267 \mathrm{KN}$ while after being given an additional hydrofoil wing at the same condition and speed results in a total resistance value (RT) of $265.5 \mathrm{KN}$. Thus the value of total vessel retention (RT) after being given the addition of hydrofoil wings is $1.5 \mathrm{KN}$ smaller compared to the total resistance (RT) value of the vessel without being given the addition of a hydrofoil wing.

\section{REFERENCES}

Tools, A. (2018). NACA 4412. Retrieved from Airfoil Tools: http://airfoiltools.com

Tupper, E. (2002). Introduction To Naval Architecture Third Edition. Great Britain: BUTTERWORTH-HEINEMANN.

Wonggiawan, F. (2015). Study of Passenger Ship Hydrofoil Design for Thousand Islands Waters. Journal of Shipping Engineering Vo.3, 28-38.

Suseno, M. (2013, Oktober 13). Air Foil. Retrieved Juni 17, 2018, from Mechanical Engineering: http://michael-suseno.blogspot.com

Stiles, R. J. (n.d.). Introduction to Aeronautics. USA: United States Air Force Academy.

Priolo, G. P. (2006). Patrol Combatant-Missile (Hydrofoil). Retrieved Juni 25, 2018, from NavSource Online: http://www.perotto.org

Nugroho, F. (2008, Oktober 21). Prinsip Penerbangan. Retrieved Juni 15, 2018, from Artikel https://www.ilmuterbang.com

Mc.CORMICK, B. W. (1995). Aerodynamics Aeronautics And Flight Mechanic. USA: John Wiley and Son

LHI. (2011). Report. Surabaya: LHI.

\section{CONCLUSION}


K.J Rawson, E. T. (2001). Basic Ship Theory Fifth Edition Vol.02. British: BUTTERWORTHHEINEMANN.

Doenhoff, I. H. (1959). Theory of Wing Section. New York: Dover Publication.
Aviation Chief. (2017). The Aerodynamics of AOA. Retrieved Juli 05, 2018, from Angle Of Attack: http://www.aviationchief.com 